\title{
Effect of holding office on the behavior of politicians
}

\author{
Daniel Enemark ${ }^{a}$, Clark C. Gibson ${ }^{b}$, Mathew D. McCubbins ${ }^{c}$, and Brigitte Seim ${ }^{\mathrm{d}, 1}$

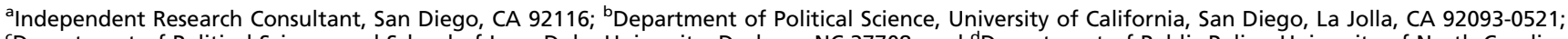 \\ 'Department of Political Science and School of Law, Duke University, Durham, NC 27708; and Department of Public Policy, University of North Carolina, \\ Chapel Hill, NC 27599-3435
}

Edited by James D. Fearon, Stanford University, Stanford, CA, and approved October 7, 2016 (received for review June 17, 2015)

\begin{abstract}
Reciprocity is central to our understanding of politics. Most political exchanges-whether they involve legislative vote trading, interbranch bargaining, constituent service, or even the corrupt exchange of public resources for private wealth-require reciprocity. But how does reciprocity arise? Do government officials learn reciprocity while holding office, or do recruitment and selection practices favor those who already adhere to a norm of reciprocity? We recruit Zambian politicians who narrowly won or lost a previous election to play behavioral games that provide a measure of reciprocity. This combination of regression discontinuity and experimental designs allows us to estimate the effect of holding office on behavior. We find that holding office increases adherence to the norm of reciprocity. This study identifies causal effects of holding office on politicians' behavior.
\end{abstract}

regression discontinuity | behavioral games | reciprocity |

legislative bargaining | corruption

$\mathbf{R}^{\mathrm{e}}$ eciprocity, the voluntary requital of benefit for benefit, is central to our understanding of politics. * From passing laws in legislatures $(1,2,10-24)$ to buying votes and favors $(3,25-35)$ to reinforcing international agreements $(36-42)$, those in political office frequently engage in the alternating provision of benefits. Theories of reciprocity in politics have their origins in social choice theory. Seeking to reconcile theoretical predictions of legislative coalition size and instability $(43,44)$ with relatively stable empirical realities (45), political scientists began to consider reciprocity as an intervening variable. The exchange of favors in a legislature, often called logrolling, is a common form of reciprocity that facilitates and stabilizes policymaking (10-17). Reciprocity also may discourage majority parties from passing rules that reduce the power of the minority, because in the future, their positions may be reversed $(2,18-22)$. Lobbyists rely on norms of reciprocity when negotiating policies with legislators $(23,24)$. Reciprocity plays a role in politics outside of lawmaking as well. International trade agreements, laws, and peace treaties rely on reciprocity (36-42). Democratic representation is a form of reciprocity, in which voters elect candidates and expect certain goods, services, or policies in exchange $(3,25-27)$. Corrupt exchanges too-especially those that occur over a period or may require repeat interaction-often rely on reciprocity (28-35). Cooperation rooted in reciprocity is fundamental to many aspects of political office.

However, the root cause of reciprocity among office holders is unclear to both scholars and policymakers (46). Does holding office cultivate reciprocity? Or do only highly reciprocating individuals choose to run for office? Understanding the origins of reciprocity is valuable for those who wish to channel its applications. From a policy standpoint, showing that institutions and cultural norms associated with holding office affect reciprocity would focus attention on institutional design or cultural interventions to affect political outcomes. However, revealing that behavioral traits, such as reciprocity, are immutable and innate would shift focus toward refining selection mechanisms for those that seek and obtain elected office.

Identifying causality in the relationship between holding office and politician behavior is precluded by two significant obstacles to obtaining valid counterfactual data for the "treatment" of holding office. First, a researcher must find a comparison group composed of individuals identical to office holders, except for not holding office. Because experimentally manipulating access to political office is challenging, current studies are unable to compare a group treated with office holding with a probabilistically equivalent untreated group. [There is an extensive experimental literature in psychology documenting the behavioral effects of power, but experimental treatments in this literature do not explicitly address the phenomena of political power and holding office (47-49).] Second, even if a valid comparison group can be found, nonoffice holders may not face the same situations as office holders-such as negotiating policies or exchanging bribes - thus preventing a comparison of the two groups on the same outcome variable.

In this project, we combat these identification challenges with a regression discontinuity design (RDD) to ensure that we have equivalent groups of office holders and nonoffice holders. We use the discontinuity at the electoral margin as an assignment mechanism for the treatment of holding office. We recruited politicians who narrowly won or lost a recent election in Zambia and asked them to make strategic decisions in a sequence of economic games designed to measure reciprocity. We find that office holders display significantly higher levels of reciprocity than nonoffice holders. This study identifies a causal effect of holding political office on individual behavior, a valuable contribution to understanding the influence of institutions on politician behavior and the genesis of the reciprocal behavior so fundamental to politics. By recruiting standing elected officials to play behavioral games, this study also relates to a growing body of research involving political elites as experimental subjects (50-52).

\section{Significance}

Does being elected to political office change an individual's behavior? Some scholars and policymakers assert that elected officials are inherently different from nonpoliticians, whereas others argue that political institutions or the culture of politics inculcate certain behaviors. We identify the effect of holding office on behavior. We recruit in-office and out-of-office politicians in Zambia to participate in behavioral games that measure reciprocity, a behavioral trait that underpins various interactions in the political arena from bribery to lobbying to legislative bargaining. We find that holding elected office causes an increase in reciprocity. The policy implication of this finding is that political institutions, culture, and incentive structures can be designed to shape the behavior and choices of society's leaders.

Author contributions: D.E., C.G., M.M., and B.S. designed research; D.E., C.G., and B.S. per formed research; D.E. and B.S. analyzed data; and D.E., C.G., M.M., and B.S. wrote the paper The authors declare no conflict of interest.

This article is a PNAS Direct Submission.

${ }^{1}$ To whom correspondence should be addressed. Email: seimbri@gmail.com.

This article contains supporting information online at www.pnas.org/lookup/suppl/doi:10. 1073/pnas.1511501113/-/DCSupplemental.

*Our definition (and experimental measure) aligns with extant literature on reciprocity in politics (1-3). Some scholars distinguish between intrinsic or generalized reciprocity (the habitual practice of repaying kindness with kindness) and instrumental or direct reciprocity (which occurs in a particular exchange with a particular partner) (4-8). Because our measure of reciprocity is based on a one-shot anonymous interaction, it measures intrinsic reciprocity rather than instrumental, consistent with existing experimental findings that a repeat interaction is not required to activate the norm of reciprocity (9). 


\section{Theory and Hypotheses}

The Connection Between Holding Office and Reciprocity. The experience of holding political office may affect a range of behaviors, but this article focuses on reciprocity. Reciprocity underlies many systems of exchange for mutual advantage. In politics, the partners in these reciprocal exchanges can be office holders, bureaucrats, nongovernmental actors, and citizens. For example, electoral representation, clientelism, patronage, and lobbying are all forms of reciprocity between political elites and citizens. Treaty law, federal grants, party organization, and logrolling are all forms of reciprocity exclusively among elites.

Office holders should be more likely to reciprocate than their nonoffice-holding counterparts, because their experience in office acculturates them to norms of reciprocity. Research in sociology and political science finds that, by holding office, a legislator is exposed to norms and learns to follow them $(46,53)$. Indeed, legislative bodies are designed to foster such norms $(19,22)$. Reciprocity is particularly important in weakly institutionalized emerging democracies, such as Zambia. Lacking the formal rules that allow citizens and their representatives to monitor and sanction elected officials, informal institutions and norms are a crucial determinant of political behavior $(54,55)$. Finally, in the Zambian context, the quid pro quo of reciprocity could certainly augment the income of a district councilor, which is an unpaid position (56).

Office holders are especially likely to rely on reciprocity in lowinformation environments. Office holders frequently must cut deals with individuals outside their community or even complete strangers. By contrast, those who do not hold office-especially in less developed, more rural states, such as Zambia-do most of their exchange within a community of relatively well-known neighbors.

Interviews with Zambian elected officials and policymakersincluding district councilors, members of the National Assembly, and the government's Office of the Auditor General-support the notion that holding the office of district councilor could foster a norm of reciprocity. Respondents suggested three reasons that holding the office of district councilor might increase reciprocity levels: party discipline, political culture, and income. First, party leaders use discipline (the practice of reward and punishment) to enforce and even exploit a reciprocity norm among those in office to pass preferred policies, maintain the status quo political system, and garner support for the next election. Second, political culture includes practices, such as legislative favor trading and pork-barrel politics, which encourage newly elected councilors to embrace reciprocal behavior as a necessary to their profession. Third, some district councilors may turn to corrupt favor trading to supplement their income, which our subjects self-reported as averaging around US\$100 per month. (Exploring these three potential mechanisms by which institutions influence behavior is an avenue for future research.)

The literature on reciprocity in politics and our interviews with politicians support the hypothesis that the treatment of holding office increases reciprocity at the individual level. ${ }^{\dagger}$

Of course, the treatment of holding office is multifaceted, and our study is not designed to identify which component of office holding is most important for cultivating reciprocity. Although it is conceivable that losing an election is part of the treatment that differentially influences the behavior of winners and losers, we do not believe that this is a factor in our study. Aside from electoral defeat itself, there is no shared experience of election

\footnotetext{
${ }^{\dagger}$ An earlier paper drew heavily on one thread of the corruption literature that argues the acquisition of power reduces prosocial behavior $(47-49,57,58)$. We therefore expected office holders to share less of their earnings in the second stage of the Trust Game. We have since reconsidered the theoretical foundations of our argument to focus on broader applications of reciprocity. Despite differences in framing regarding the effect of holding office on behavior, every version of this paper uses exactly the same data, models, and tests.
}

losers; whereas office holders conduct council meetings, hire and fire staff, make policy decisions, and attend national conferences and workshops, election losers do not gather together or participate in any institutions. Neither the academic literature nor our interviews with Zambian officials suggest that election losers might systematically and differentially develop new norms of behavior.

Measuring Reciprocity. We use costly choices in behavioral games to measure reciprocity among political officials. Specifically, to disentangle reciprocity from alternative other-regarding preferences, we used three strategic decision tasks set within the Trust Game and Dictator Game. A substantial literature in the behavioral sciences suggests that the experimental tasks in which our subjects engage are reliable, if sometimes noisy, indicators of fundamental behavioral tendencies. Behavior in the Trust and Dictator Games is used to explain human behavior in the fields of psychology (59-62), anthropology $(63,64)$, neuroscience and evolutionary biology (65-67), economics (68-70), and political science $(3,33,34,71-74)$. Transfers in these games predict a wide range of real world behavior $(75,76)$, including turnout (77), charitable donations (78), and propensity to repay loans (79). In our study, behavioral games are valuable because they allow us to observe choices made by both winners and losers in the same environment.

To measure reciprocity, we combine a Trust Game and a Dictator Game. The Trust Game begins with two players, both endowed with 5,000 Zambian Kwacha (about 2.5 h of wages for our median participant). The two players are matched randomly and anonymously, and they are in different rooms, so that no player knows the identity of her partner. In stage 1, player 1 may transfer any amount of her initial endowment to player 2, and this transfer is tripled before the second player receives it. In stage 2, the tripled transfer is added to player 2's initial endowment, and player 2 may return any nonnegative amount of the total to player 1 .

In the Dictator Game, two players are matched randomly and anonymously with a different person in the other room. The Dictator Game has the same endowment and choice structure as Trust Stage 2. The subjects of our experiments played the Dictator Game after the Trust Game, with several tasks in between. In both games, the rules (the actions, payoffs, and information available to both players) are common knowledge to both players.

In our experiments, we fixed each player's monetary endowment in the Dictator Game to be identical to that in Trust Stage 2. Thus, the only difference between these two tasks is an implicit framing of reciprocity. In Trust Stage 2, the subject knows that an anonymous and randomly assigned partner in another room determined her endowment. In the Dictator Game, she knows that the researcher determined her endowment. We develop an indicator of reciprocity by taking the difference between a subject's transfer in Trust Stage 2 and the Dictator Game and dividing it by her endowment (which is constant across these tasks). We call this the "reciprocity score," representing reciprocal behavior after removing the generosity component $(3,4)$. The "trust score" is the amount transferred in Trust Stage 1 by player 1 (divided by player 1's endowment), a measure of how willing a politician is to send money to another individual without knowing whether she will reciprocate. The "generosity score" is the amount transferred in the Dictator Game (divided by endowment), a measure of how willing a politician is to give something to another individual without the perceived obligation of reciprocity. Fig. 1 shows the distribution of these three variables: the trust score, the generosity score, and the reciprocity score.

Although existing literature provides a clear prediction for the effect of holding office on reciprocity scores, it does not provide predictions for generosity or trust scores (behavior in the Dictator and Trust Stage 1 tasks, respectively). Political scientists generally model politicians as self-interested, and therefore, we might 


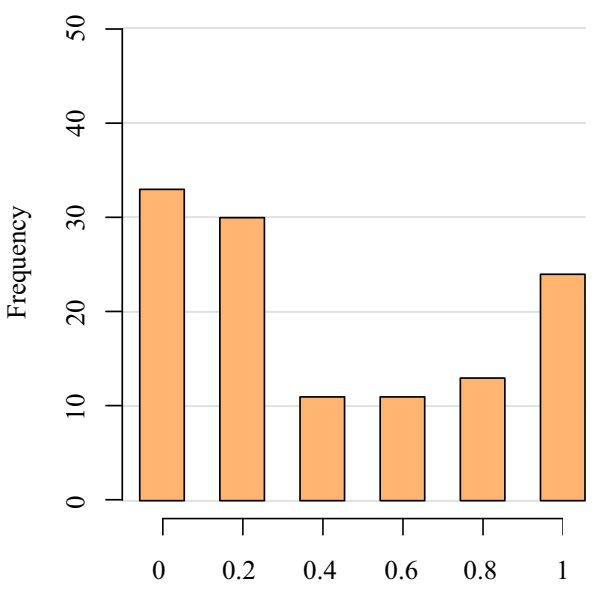

Trust Scores
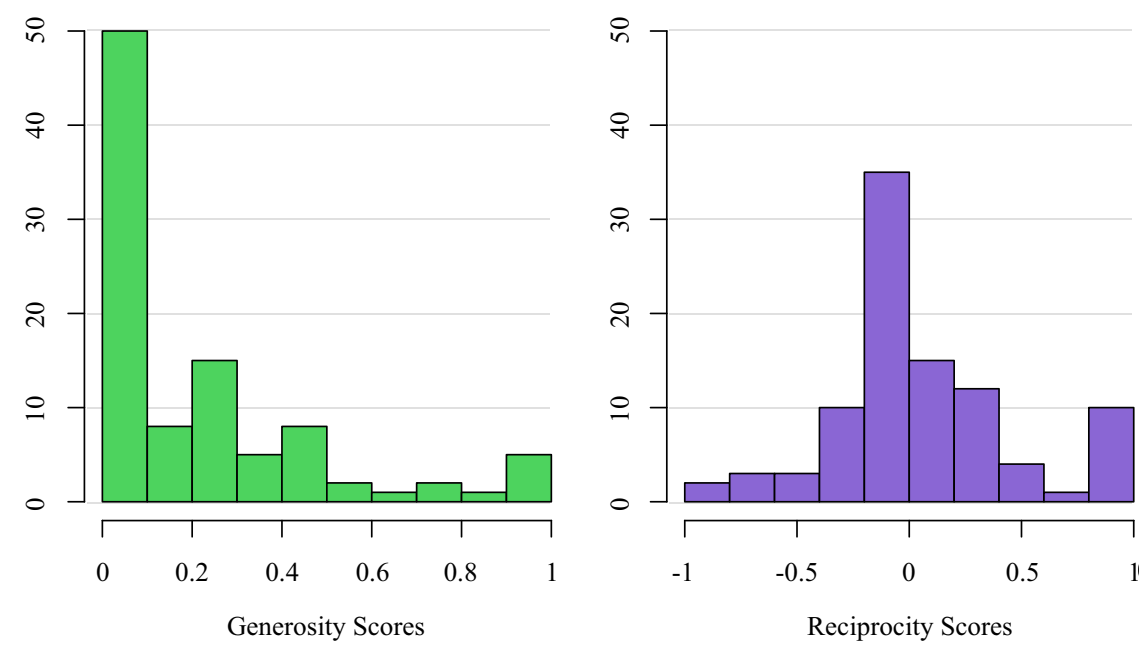

Fig. 1. Histogram of trust, generosity, and reciprocity scores.

expect generosity and trust, which are economically irrational in equilibrium, to be low among our participants. However, whereas political scientists describe legislative institutions as fostering reciprocity, we are not aware of any works arguing that these institutions foster or suppress generosity or trust, meaning that this literature does not lead us to believe that the experience of holding office should cause close winners to differ systematically from close losers. In addition, although our interviewees described reciprocity as a crucial trait for officials, they said nothing of trust or generosity, validating our lack of focus on the trust score and generosity score effects.

\section{Analysis}

We had a unique opportunity to use behavioral experiments to test the effect of office holding in Zambia. With the endorsement of the Local Government Association of Zambia, we invited 346 politicians who had run for district council in the most recent election and won or lost by $10 \%$. We were able to recruit 143 of 346 politicians $(41 \%)$ from all over Zambia to a conference center in Lusaka to participate in our research. District councils in Zambia consist of 8-28 councilors who control an average budget of about $\$ 500,000$ or 326 times Zambia's income per capitaenough money that council decisions can significantly affect the daily lives of citizens. When councilors build coalitions with their peers to pass policy, they face little oversight from any other level of government $(80,81)$. In brief, district councilors in Zambia make choices important to the welfare of their constituents without extensive institutional constraints.

We used an electoral RDD to identify individuals who could serve in treatment and control groups for the treatment of holding political office. This design works because at the electoral margin winners and losers are indistinguishable but for the fact of having obtained office. (SI Appendix has discussion of this technique and evidence that our two groups were, in fact, balanced across 24 covariates.) We drew our subjects from the pool of Zambian political elites who ran for district council and won or lost by $10 \%$ or less. This recruitment strategy essentially "hard-coded" our chosen bandwidth for analysis, preventing us from manipulating the bandwidth to obtain significant results.

Following recent literature on RDDs (82), we use a linear model to identify the effect of office holding on reciprocity:

$$
y_{i}=\beta_{0}+\beta_{1} T_{i}+\beta_{2} V_{i}+\varepsilon .
$$

Here, the treatment $T_{i}$ is a dummy variable indicating whether subject $i$ holds office; the dependent variable $y_{i}$ is the reciprocity score, and the forcing variable $V_{i}$ is the margin of victory. There are small amounts of data missing because of subjects using the restroom or taking urgent telephone calls. Winners and losers were equally likely to miss experimental tasks, so even if this missingness is nonrandom with respect to reciprocity, it would not bias our findings unless the correlation between reciprocity and missingness were different for winners and losers.

\section{Results}

We find that holding office significantly affects the behavior of politicians. As expected, there is a significant effect of holding office on reciprocity scores. The results of our regressions appear in Table $1 .^{\ddagger}$ Fig. 2 depicts graphically the discontinuity in reciprocity score at the cut point using Epanechnikov kernel-weighted local mean estimation.

We do not find a behavioral effect of holding office on trust or generosity scores, which aligns with the literature cited above that focuses on reciprocity rather than trust or generosity. These null effects show that holding office does not cause politicians to trust anonymous partners more or sacrifice for the sake of fairness or generosity. Together with the positive effect on reciprocity, these results show that office holding seems to train officials in the norm of "you scratch my back, I scratch yours," but it does not condition them to initiate the exchange or give without the perceived obligation of reciprocity.

We recruited only individuals close to the cutoff, and we determined our estimation technique before we entered the data, so the typical concern with RDDs-that the researcher might choose a bandwidth and model specification to obtain a significant result-is not applicable to this case. Also, Fig. 2 illustrates graphically that the regression discontinuity does not depend on values far from the cut point.

We perform a number of robustness checks using alternative model specifications (details are in SI Appendix). Our model is robust to the inclusion of an interaction term between the treatment and forcing variable (victory status and vote share, respectively). Gelman and Imbens (82) argue that it is not necessary (or even appropriate) to include higher-order polynomial

\footnotetext{
${ }^{\ddagger}$ The sample size in these regressions is 95. As explained in Materials and Methods, we recruited 143 individuals but excluded from the analysis 18 individuals who failed the comprehension quizzes. Of the remaining 125 individuals, we are unable to compute a reciprocity score for 30, because they could not complete the Dictator Game for reasons unrelated to subject characteristics or choices in the games. (On $1 \mathrm{~d}$, there was a logistical issue at the hotel where we ran the experiment, which prevented us from reaching the end of our protocol.)
} 


\section{Table 1. Regression results}

\begin{tabular}{lrcc} 
Variables & \multicolumn{1}{c}{ Trust } & Generosity & \multicolumn{1}{c}{ Reciprocity } \\
\hline Winner & $-0.128(0.140)$ & $0.009(0.115)$ & $0.356 * *(0.171)$ \\
Margin & $0.177(1.253)$ & $-0.524(1.030)$ & $-2.211(1.529)$ \\
Constant & $0.488 * * *(0.079)$ & $0.204 * * *(0.066)$ & $-0.081(0.098)$ \\
Observations & 122 & & 95 \\
$R^{2}$ & 0.021 & 97 & 0.050 \\
Adjusted $R^{2}$ & 0.005 & -0.013 & 0.029 \\
\hline
\end{tabular}

$P$ values are noted $(* * P<0.05 ; * * * P<0.01)$.

functions of the forcing variable, but in the interest of transparency, we include models with up to third-level polynomials with and without interaction terms. (The treatment effect of holding office on reciprocity is significant when we add a quadratic term but not a cubic term.)

As another robustness check, we stack the Dictator and Trust Games player 2 choices to examine how playing the Trust Game compared with the Dictator Game might affect office holders differently. This model supports our finding; office-holding politicians give a significantly higher percentage of their endowment than nonoffice holders in the second stage of the Trust Game but not the Dictator Game, whereas election losers behave consistently across these two tasks. The results also hold when we use subjects' second-stage transfers in the Trust Game (controlling for endowment) as the dependent variable-a slightly different operationalization of reciprocity, one that bundles quid pro quo reciprocity and generosity. Finally, when we include participants who scored poorly on comprehension quizzes, the estimated treatment effect is unchanged, but the $P$ value slightly increases, supporting our expectation that including subjects who do not understand the task is equivalent to adding stochastic noise.

\section{Discussion}

The results provide evidence that the experience of holding office changes behavior. More specifically, our findings show that office-holding politicians exhibit more reciprocity than those who ran for office but lost the election. This finding and the null findings for trust and generosity align with the political science literature that claims that adherence to the norm of reciprocity is critical for success in politics and that the failure to reciprocate trust is a greater transgression than the failure to trust. As in gambling, the penalty for welching is greater than the penalty for refusing to play. Future research can continue to unpack the relationships between diverse behavioral traits and the treatment of holding elected office.

The RDD identification strategy allows us to claim that the difference in behavior associated with holding office is not likely attributable to chance or confounding differences between our treatment and control groups. Although interview data suggest that the effect of holding office on reciprocity would be unaffected by the size of the electoral win, we note that our findings may not generalize to all elections and officials.

Our study indicates a causal relationship between holding office and reciprocity, and a number of different mechanisms may be driving this result. As discussed above, interviewed Zambian officials point to party discipline, political culture, and income as possible mechanisms. Although some respondents stated that parties encourage the adherence to behavioral norms among office holders, party discipline in Zambia is actually very low (83), which may suggest that this mechanism is likely weakest in explaining our result. The explanation that elected officials observe and emulate a culture of reciprocity after they are in office (political culture) is more plausible and more consistent with existing research $(46,53)$.
Beyond those suggested by Zambian interview subjects, other causal mechanisms may be at play as well. Holding office may stimulate the reciprocity of Zambian legislators in the style of "big man" politics prevalent in Africa (84). Alternatively, gaining office may cultivate within Zambian district councilors a feeling of kinship toward the citizens in their district, causing elected officials to express a higher level of reciprocity toward their constituents (85-87). Again, however, considering that the players of the study's games were members of lower-funded and constitutionally constrained district councils, the view that holding office leads to an ennobling effect that increases reciprocity may not be persuasive $(35,85)$. Disentangling these mechanisms is an avenue for future research.

In each task, subjects in our experiments were told that they were paired with "another person." We described their partners using this neutral, anonymity-preserving language for three reasons: $(i)$ we did not want to create experimenter demand by using loaded descriptors, such as "fellow politician"; (ii) the existing literature showing the external validity of behavioral games draws from games with anonymous pairing and neutral framing; and (iii) we were not solely interested in politicians' behavior toward their peers. (SI Appendix elaborates on these three points.) For all of these reasons, we felt that maintaining the anonymity of subjects' partners would increase our ability to learn from the study theoretically. In future research, randomizing the identity of subjects' partners could provide insight as to whether reciprocity is cultivated through particular relationships or attitudes toward a specific class of people.

By constructing an experiment that allows us to measure observable behavior among office holders and nonoffice holders and creates a valid counterfactual group for comparison with office holders, our research presents an empirical contribution toward a better understanding of the origins of the behavior of elected officials. More specifically, we view our results as compelling evidence that holding office does indeed change the behavioral tendencies of those in elected office, specifically by increasing their reciprocity. Finding an effect of holding office on behavior in this research context is intriguing; if holding even a lower-level legislative office in a weakly institutionalized country can change an individual's behavior, the potential behavioral effects of holding office at higher levels of responsibility and in stronger political systems may be even greater. Furthermore, although our measure of reciprocity did not allow for repeat interaction or the possibility of sanctions, office holders in our study

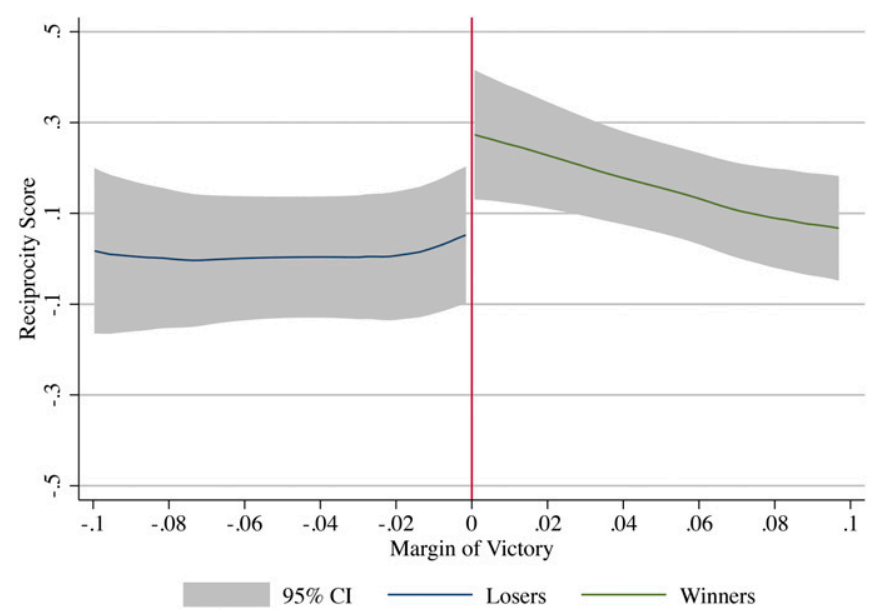

Fig. 2. Discontinuity in reciprocity scores across the electoral victory margin. Epanechnikov kernel-weighted local mean estimation with 95\% confidence intervals (95\% Cls). 
were nonetheless poised and ready to engage in reciprocal exchanges. As a policy implication, this paper provides evidence that behavioral traits can be cultivated (or repressed) in political leaders. To shape political outcomes, policymakers can address the institutions, culture, and incentives of office holding in addition to or perhaps, instead of addressing how leaders are selected.

\section{Materials and Methods}

The methods used in this study include four major elements: (i) research design, (ii) recruitment procedures, (iii) experimental protocols, and (iv) subject comprehension of instructions [the following information is also available: replication $\mathrm{R}$ code (Dataset S1), replication Stata code (Dataset S2), the dataset for replicating regression results (Dataset S3), the dataset for replicating covariate balance (Dataset S4), and discussion of additional analysis and methods (SI Appendix)].

First, we use an RDD as an assignment mechanism for the treatment of holding office, allowing us to identify at the electoral margin the treatment effect of holding office on strategic choices. This design determined our population of interest-politicians who narrowly won or lost council elections. The forcing variable in our RDD is margin of victory in the last district government election, and we recruited candidates in a bandwidth of $\pm 10 \%$. In SI Appendix, we provide an overview of the literature on RDDs using elections and argue that the design is appropriate in our case, because $(i)$ the officials in this study do not have enough information to manipulate their efforts to obtain a bare majority, and (ii) we have strong evidence that the election was free and fair (88).

In the typical RDD, the analyst has observational data for cases along the entire spectrum of the forcing variable and must select a bandwidth around the cut point within which to conduct the analysis. We did not have the luxury of using extant data to measure reciprocity; instead, we had to recruit subjects to a conference center, where we could use an experiment to collect behavioral data from which we calculated the reciprocity score. This procedure was costly, so instead of recruiting politicians from across the full spectrum of the forcing variable, we only recruited politicians within $10 \%$ of the electoral cut point. Thus, we prespecified our bandwidth before data collection began and only collected outcome data within this bandwidth.

As a result, there are no real bandwidth choices to be made, because (ii) we only collected data from individuals close to the cutoff, and (ii) we could not recruit enough individuals to tighten the bandwidth without losing statistical power. The first point is a virtue of our design; by hard coding the bandwidth into the sampling procedure, we guard against post hoc manipulation of bandwidth ( $p$ hacking for results). The second point is a necessity of our design; we picked the smallest bandwidth that would allow us to assemble a sample of politicians large enough for causal inference. Our subject pool, although larger than any group of political elites ever recruited for behavioral experiments, is too small to allow for meaningful robustness checks using smaller bandwidths. However, in SI Appendix, we show covariate balance between the treatment and control groups across 24 observable covariates, supporting the validity of our bandwidth selection (89).

Second, we designed a recruitment procedure to draw as large and unbiased a sample as possible from our theoretical population of interest-346 candidates who ran for district council in the 2006 Zambian elections and won or lost by less than $10 \%$. We sent letters endorsed by the Zambian Government to every district council asking for assistance in locating candidates in this population. We then called the district commissioner or mayor

1. Cohen L, Malloy CJ (2014) Friends in high places. Am Econ J Econ Policy 6(3):63-91.

2. Carlin RE, Love GJ (2011) The politics of interpersonal trust and reciprocity: An experimental approach. Springer Science Business Media 35(1):43-63.

3. Finan F, Schechter L (2012) Vote-buying and reciprocity. Econometrica 80(2):863-881.

4. Sobel J (2005) Interdependent preferences and reciprocity. J Econ Lit 43(2):392-436.

5. Gouldner AW (1960) The norm of reciprocity: A preliminary statement. Am Sociol Rev 25(2):161-178.

6. Jacobson S, Petrie R (2014) Favor trading in public goods provision. Exp Econ 17(3):439-460

7. Alexander RD (1987) The Biology of Moral Systems (Aldine de Gruyter, New York).

8. Trivers RL (1971) The evolution of reciprocal altruism. $Q$ Rev Biol 46(1):35-58.

9. McCabe KA, Smith VL (2003) Strategic analysis in games: What information do players use? Trust \& Reciprocity: Interdisciplinary Lessons from Experimental Research, eds Ostrom E, Walker J (Russel Sage Foundation Publications, New York).

10. Schneier EV (1988) Norms and folkways in Congress: How much has actually changed? Congress and the Presidency 15(2):117-138.

11. Bratton KA, Rouse $S$ (2011) Networks in the legislative arena: How group dynamics affect cosponsorship. Legis Stud Q 36(3):423-460.

12. Fowler JH (2006) Connecting the Congress: A study of cosponsorship networks. Polit Anal 14(4):456-487.

13. Tullock $G$ (1963) General irrelevance of the general impossibility theorem. $Q J$ Econ 81(2):256-270 of each province, who typically gave us councilors' telephone numbers directly. Where we could not reach a district office, we broadcasted announcements on the radio. These attempts yielded a contact rate of $43 \%$. Of the candidates that we contacted, 95\% (143 subjects-79 winners and 64 losers) participated in the experiment. This high response rate alleviates concerns that selection into the sample is correlated with our outcome of interest: reciprocity.

Third, we wrote, translated, tested, and refined our experimental protocols. ${ }^{+}$We went to great lengths to run the experiments in an environment that resembles as closely as possible the environment in which our subjects make their political decisions (conference rooms in urban areas) and set monetary payments in the games high enough to incentivize thoughtful decision-making. We tested our experimental protocols with undergraduate students in the United States and at the University of Zambia and a small sample of politicians outside our theoretical population. The experiments were carried out using paper and pencil. Each session had $\sim 20$ subjects and lasted for under $2 \mathrm{~h}$. In each activity, we randomly and anonymously paired subjects with someone in another location and reminded them of this setup every time that they made a decision. We emphasized these points to prevent their behavior from being affected by friend, familial, or tribal ties of someone in their room. The subjects received no information that would condition their beliefs about who this other player might be other than the handouts provided in both English and a Zambian language, which likely suggested to them that the players were all Zambian. We, therefore, interpret the actions in the game to be representative of politicians' choices when playing with Zambians in general, whether politician or citizen. This construction also implies that subjects were unable to select into different groups or paths of the research.

Fourth, we measured subjects' comprehension of instructions and conducted our analysis after removing data from subjects who could not show sufficient levels of understanding. We cannot draw conclusions about a subject's behavior if he is acting under some unknown, mistaken belief about the incentives that he faces (90). To measure comprehension, subjects took a pretest survey that evaluated their arithmetic skills, and they were frequently quizzed on their understanding of instructions, earning money for correct answers. We used quiz answers to restrict our sample to include only those subjects who showed that they understood the rules of the games, and ultimately, we removed 18 participants with low quiz scores, leaving a sample of 125

We received ethical approval on this study from the institutional review board at the University of California, San Diego, the institution of all four authors at the time of the field research. All subjects signed an informed consent document before participating in our research. In addition, they were reminded before making each decision that their choices would be anonymous and that we were recording no identifying information with their data.

ACKNOWLEDGMENTS. We thank Robert Bond, Micah Gell-Redman, Rupal Mehta, Adeline Lo, Nicholas Obradovich, and Amanda Robinson for suggestions, and Langche Zeng for feedback on our preanalysis model specifications. Special thanks to our project manager in Zambia, Garikai Membele; research assistants Leslie Chikuta, Ronald Kaunda, David Makondo; Maurice Mbolela of the Local Government Association of Zambia; Peter Loloji at the University of Zambia; and the staff at the Zambia Electoral Commission and Office of the Auditor General. Thanks also to our US-based research assistants: Alex Blanning, Shannon Colin, and Wesley Cox. This research was supported by the National Science Foundation.

14. Hahn V, Mühe F (2009) Committees and reciprocity. Math Soc Sci 57(1):26-47.

15. Kirkland JH, Williams RL (2014) Partisanship and reciprocity in cross-chamber legislative interactions. J Polit 76(3):754-769.

16. Fenno RF (1997) Learning to Govern: An Institutional View of the 104th Congress (Brookings Institution, Washington, DC).

17. Rabin M (1993) Incorporating fairness into game theory and economics. Am Econ Rev 83(5):1281-1302.

18. Martorano N (2004) Cohension or reciprocity? Majority party strength and minority party procedural rights in the legislative process. State Polit Policy Q 4(1):55-73.

19. Weingast BR, Marshall WJ (1988) The industrial organization of congress; or, why legislatures, like firms, are not organized as markets. J Polit Econ 96(1):132-163.

20. Shepsle KA, Weingast BR (1987) The institutional foundations of committee power. Am Polit Sci Rev 81(1):85-104.

21. Binder SA (1997) Minority Rights, Majority Rule, Partisanship and the Development of Congress (Cambridge Univ Press, Cambridge, UK).

22. Weingast BR (1979) A rational choice perspective on congressional norms. Am J Pol Sci 23(2):245-262.

23. Susman TM (2008) Private ethics, public conduct: An essay on ethical lobbying, campaign contributions, reciprocity, and the public good. Stanford Law Pol Rev 19(1):10-22.

24. Cialdini RB (2010) Influence: Science and Practice (Allyn \& Bacon, Needham Heights, MA), 4th Ed. 
25. Keefer P, Vlaicu R (2008) Democracy, credibility, and clientelism. J Law Econ Organ 24(2):371-406.

26. Lemarchand R (1972) Political clientelism and ethnicity in tropical Africa: Competing solidarities in nation-building. Am Polit Sci Rev 66(1):68-90.

27. Nichter S (2014) Conceptualizing vote buying. Elect Stud 35:315-327.

28. Tanzi V (1998) Corruption around the world: Causes, consequences, scope and cures IMF Surv 45(4):559-594.

29. Abbink K (2004) Staff rotation as an anti-corruption policy: An experimental study Eur J Polit Econ 20(4):887-906.

30. Warren ME (2004) What does corruption mean in a democracy? Am J Pol Sci 48(2): 328-343.

31. Lambsdorff JG (2008) Global Corruption Report 2008: Corruption in the Water Sector (Transparency International and Cambridge Univ Press, Cambridge, UK).

32. Lambsdorff JG (2007) The Institutional Economics of Corruption and Reform (Cambridge Univ Press, Cambridge, UK).

33. Lambsdorff JG (2012) Behavioral and experimental economics as a guidance to anticorruption. New Advances in Experimental Research on Corruption, eds Serra D, Wantchekon L (Emerald Group Publishing, Bingley, UK), pp 279-300.

34. Abbink K, Serra D (2012) Anticorruption policies: lessons from the lab. New Advances in Experimental Research on Corruption, eds Serra D, Wantchekon L (Emerald Group Publishing, Bingley, UK), pp 77-116.

35. Rothstein B (2013) Corruption and social trust: Why the fish rots from the head down. Soc Res (New York) 80(4):1009-1032.

36. Keohane RO (1986) Reciprocity in international relations. Int Organ 40(1):1-27.

37. Keohane RO (2001) Governance in a partially globalized world. Am Polit Sci Rev 95(1): $1-13$.

38. Bagwell K, Staiger RW (2001) Reciprocity, non-discrimination and preferential agreements in the multilateral trading system. Eur J Polit Econ 17(2):281-325.

39. Paris F, Ghei N (2003) The role of reciprocity in international law. Cornell Int Law J 36:93.

40. Simmons B (2010) Treaty compliance and violation. Annu Rev Polit Sci 13:273-296.

41. Rhodes $C$ (1989) Reciprocity in trade: The utility of a bargaining strategy. Int Organ 43(2):273-299.

42. Bagwell K, Staiger RW (2015) Delocation and trade agreements in imperfectly com petitive markets. Res Econ 69(2):132-156.

43. Riker WH (1962) The Theory of Political Coalitions (Yale Univ Press, New Haven, CT)

44. McKelvey R (1976) Intransitivities in multidimensional voting models and some implications for agenda control. J Econ Theory 12(3):472-482.

45. Tullock G (1981) Why so much stability? Public Choice 37(2):189-202

46. Asher HB (1973) The learning of legislative norms. Am Polit Sci Rev 67(2):499-513.

47. Anderson C, Jennifer BL (2002) The experience of power: Examining the effects of power on approach and inhibition tendencies. J Pers Soc Psychol 83(6):1362-1377.

48. Kipnis D (1972) Does power corrupt? J Pers Soc Psychol 24(1):33-41.

49. DeCelles KA, DeRue DS, Margolis JD, Ceranic TL (2012) Does power corrupt or enable? When and why power facilitates self-interested behavior. J Appl Psychol 97(3):681-689.

50. Butler DM, Kousser T (2015) How do public goods providers play public goods games? Legis Stud Q 40(2):211-240.

51. Hafner-Burton EM, LeVeck BL, Victor DG, Fowler JH (2014) Decision maker preferences for international legal cooperation. Int Organ 68(4):845-876.

52. Milner HV, Nielson DL, Findley MG (2016) Citizen preferences and public goods: Comparing preferences for foreign aid and government programs in Uganda. Rev Int Organ 11(2):219-245.

53. Reiser M, Hülsken C, Schwarz B, Borchert J (2011) Das reden der neulinge und andere sünden. parlamentarische sozialisation und parlamentskultur in zwei Deutschen landtagen. Z Parlamentsfragen 42(4):820-834.

54. Chikulo BC (2014) Decentralization reforms in Zambia 1991-2010. J Soc Sci 40(1): 95-105.

55. Nakagawa H (2013) Three Essays on Development Economics. Available at https:// escholarship.org/uc/item/82h5j3p6. Accessed October 25, 2016.

56. Ermisch J, Gambetta D (2016) Income and trustworthiness. Sociol Sci 3:710-729.

57. Klitgaard R (1988) Controlling Corruption (Univ of California Press, Berkeley, CA).

58. Rothstein B, Eek D (2009) Political corruption and social trust: An experimental approach. Ration Soc 21(1):81-112.

59. Shariff AF, Norenzayan A (2007) God is watching you: Priming God concepts increases prosocial behavior in an anonymous economic game. Psychol Sci 18(9):803-809.
60. Keysar B, Converse BA, Wang J, Epley N (2008) Reciprocity is not give and take: Asymmetric reciprocity to positive and negative acts. Psychol Sci 19(12):1280-1286.

61. Rigdon M, Ishii K, Watabe M, Kitayama S (2009) Minimal social cues in the dictator game. J Econ Psychol 30(3):358-367.

62. Sloane S, Baillargeon R, Premack D (2012) Do infants have a sense of fairness? Psychol Sci 23(2):196-204.

63. Marlowe FW (2004) What explains Hadza food sharing? Socioeconomic Aspects of Human Behavioral Ecology, ed Alvard M (Emerald Group Publishing Limited, Bingley, UK), pp 69-88.

64. Henrich J, et al. (2006) Costly punishment across human societies. Science 312(5781): $1767-1770$

65. Hoffman E, McCabe K, Smith VL (1996) Social distance and other-regarding behavior in dictator games. Am Econ Rev 86(3):653-660.

66. Andreoni J, Versterlund $L$ (2001) Which is the fairer sex? Gender differences in altruism. $Q J$ Econ 116(1):293-312.

67. Israel S, et al. (2009) The oxytocin receptor (OXTR) contributes to prosocial fund allocations in the dictator game and the social value orientations task. PLoS One 4(5): e5535.

68. Frey BS, Bohnet I (1995) Institutions affect fairness: Experimental investigations. J Inst Theor Econ 151(2):286-303.

69. Bardsley N, Moffatt PG (2007) The experimetrics of public goods: Inferring motivations from contributions. Theory Decis 62(2):161-193.

70. Whitt S, Wilson RK (2007) The dictator game, fairness and ethnicity in postwar Bosnia. Am Pol Sci 51(3):655-668.

71. Fowler JH (2005) Altruistic punishment and the origin of cooperation. Proc Natl Acad Sci USA 102(19):7047-7049.

72. Glaeser E, Laibson D, Scheinkman J, Soutter C (2000) Measuring trust. Q J Econ 115(3): 811-846.

73. Bowles S, Gintis H (2002) Homo reciprocans. Nature 415(6868):125-128.

74. Robinson AL (February 26, 2016) Nationalism and interethnic trust: Experimental evidence from an African border region. Comp Polit Sci, 10.1177/0010414016628269.

75. Fehr E, Gächter S (2002) Altruistic punishment in humans. Nature 415(6868):137-140.

76. Baran N, Sapienza P, Zingales L (2010) Can we infer social preferences from the lab? Evidence from the Trust Game. Working paper 10-02. (Chicago Booth Research, Hyde Park, Chicago). Available at ssrn.com/abstract $=1540137$.

77. Fowler JH (2006) Altruism and turnout. J Polit 68(3):674-683.

78. Benz M, Meier S (2008) Do people behave in experiments as in the field? Evidence from donations. Exp Econ 11(3):268-281.

79. Karlan D (2005) Using experimental economics to measure social capital and predict financial decisions. Am Econ Rev 95(5):1688-1699.

80. Chisholm D (1989) Coordination Without Hierarchy: Informal Structures in Multiorganizational Systems (Univ of California Press, Berkeley, CA).

81. Gibson CC, Hoffman BD (2013) Coalitions not conflicts: Ethnicity, political institutions, and expenditure in Africa. Comp Polit 45(3):273-290.

82. Gelman A, Imbens G (2014) Why high-order polynomials should not be used in regression discontinuity designs. Working paper 20405 (National Bureau of Economic Research, Cambridge, MA). Available at www.nber.org/papers/w20405.pdf.

83. Randall V, Svåsand L (2002) Political parties and democratic consolidation in Africa. Democratization 9(3):30-52.

84. Diamond L (2008) The rule of law versus the big man. J Democracy 19(2):138-149.

85. Price TL (2003) The ethics of authentic transformational leadership. Leadersh Q 14(1): $67-81$

86. Drazen A, Ozbay EY (2016) Does "being chosen to lead" induce non-selfish behavior? Experimental evidence on reciprocity. Discussion paper DP11338 (Centre for Economic Policy Research, London). Available at www.cepr.org/active/publications/discussion_papers/ dp.php?dpno $=11338$.

87. Burns JM (1978) Leadership (Harper \& Row, New York).

88. Caughey DM, Sekhon JS (2011) Elections and regression discontinuity design: Lessons from close U.S. house races, 1942-2008. Polit Anal 19(4):385-408.

89. Eggers AC, Fowler A, Hainmueller J, Hall AB, Snyder JM (2014) On the validity of the regression discontinuity design for estimating electoral effects: New evidence from over 40,000 close races. Am J Pol Sci 59(1):259-274.

90. Chou E, McConnell M, Nagel R, Plott C (2009) The control of game form recognition in experiments: Understanding dominant strategy failures in a simple two person 'guessing' game. Exp Econ 12(2):159-179. 